Cadernos de Clio, Curitiba, n. ${ }^{\circ}$ 2, 2011

\title{
OS ESTADOS UNIDOS POR INTEIRO: teorias explicativas e discursos de posses presidenciais da Guerra Fria - Roosevelt a Bush (1945-1989) ${ }^{1}$
}

\author{
Tatiana Spalding Perez
}

Resumo: Jean-Pierre Fichou, em sua obra "A civilização Americana" (La civilizasation américaine), analisa as teorias explicativas dos Estados Unidos através do resgate de seus componentes essenciais e da compreensão de seu caráter cultural, demonstrando como esses, apesar das mudanças de contexto, se mantiveram como princípios fundamentais para a definição do interesse nacional e para a formulação das políticas norteamericanas. A análise aqui apresentada parte dos discursos de posse dos presidentes dos Estados Unidos do período da Guerra Fria (de Roosevelt, 1945 a Bush, 1989) para demonstrar os princípios mais fortemente defendidos nesse contexto pela sociedade americana democracia, voluntarismo, abundância, dinamismo, capitalismo e expansionismo.

Palavras-chave: Jean-Pierre Fichou. Estados Unidos. Guerra Fria. Cultura. Política.

Os Estados Unidos sustentam sua identidade nacional defendendo que a sociedade americana ${ }^{2}$ é fiel a princípios morais

\footnotetext{
${ }^{1}$ A primeira versão desse artigo foi produzida como requisito para aprovação na disciplina de "História dos Estados Unidos" ministrada pela professora Susana Bleil na Universidade Federal do Rio Grande do Sul (UFRGS) no primeiro semestre de 2010. A escolha do autor foi realizada pela professora.
} 
Cadernos de Clio, Curitiba, n. ${ }^{\circ} 2,2011$

expressos no seu estilo de vida. Tais princípios fazem parte também da tradição política norte-americana, que o utiliza para sustentar suas ações. Durante a Guerra Fria, por exemplo, os presidentes dos Estados Unidos fizeram uso em seus discursos da defesa desses princípios para legitimar a constante disputa com a União Soviética.

A Segunda Guerra Mundial levou ao fim das antigas potências européias (França, Inglaterra e Alemanha) como centro do sistema internacional. O conflito, entretanto, não afetou negativamente todas as nações mundiais. Conforme Paulo Vizentini (2006), os Estados Unidos emergiram como os maiores beneficiados, pois o conflito reativou e expandiu sua economia, tornando-a mundialmente dominante. . Por outro lado, a União Soviética elevou seu prestígio diplomático e militar, devido ao papel que exerceu na derrota da Alemanha nazista, ampliou sua esfera de influência junto às suas fronteiras européias e teve seu poder acentuado com o fortalecimento global da esquerda e com a presença do Exército Vermelho no centro da Europa e no Extremo Oriente. Como principal conseqüência, o

2 É preciso ressaltar que, tradicionalmente, os cidadãos "estado-unidenses" são denominados "norte-americanos" ou simplesmente "americanos". Sabemos que nem a América do Norte, nem a América como um todo se constitui apenas dos Estados Unidos, entretanto, como coloca Leandro Karnal (2008), nenhum outro país utiliza tais expressões para definir sua nacionalidade, por isso sua utilização nos estudos acadêmicos não gera confusão no reconhecimento de qual país se trata ao se usar os termos "americanos" ou "norte-americanos" ao nos referirmos aos Estados Unidos e à sua sociedade. 
fim da Segunda Guerra Mundial levou à Guerra Fria, constituída, essencialmente, pela oposição entre Estados Unidos e União Soviética como potências líderes do sistema internacional.

Apesar da disputa entre Estados Unidos e União Soviética não ter resultado em uma Terceira Guerra Mundial e os conflitos diretos terem ficado limitados apenas a países em desenvolvimento, considerados na época como de terceiro mundo, o termo Guerra é bem aplicado ao período. Afinal, como observou Thomas Hobbes em sua obra "O Leviatã", "a guerra consiste não só na batalha, ou no ato de lutar: mas num período de tempo em que a vontade de disputar pela batalha é suficientemente reconhecida" (HOBBES apud HOBSBAWM, 1995: 224). Segundo Philip Abbott (1991), o sistema bipolar sustentava a Guerra Fria, pois intensificava a disputa ao levar à percepção de que havendo dois lados no conflito, apenas um poderia sair vencedor enquanto o outro deveria ser derrotado.

Para Eric Hobsbawm (1995), a Guerra Fria fundamentava-se na crença ocidental de que a Era da Catástrofe não chegara ao fim, de que o futuro do capitalismo e de sua sociedade não estavam assegurados, devido a experiência do pós-Primeira Guerra Mundial ${ }^{3}$. Além disso, para o historiador, os Estados Unidos temiam que os

\footnotetext{
${ }^{3}$ Após o término da Primeira Guerra Mundial, os Estados Unidos voltaram a sua antiga posição isolacionista no contexto mundial, não participando do processo de construção da paz, o que extinguiu qualquer possibilidade de estabilidade do sistema internacional, segundo Pecequilo (2005).
} 
países europeus, devastados pela guerra, estivessem mais dispostos à radicalização através da revolução social e de políticas econômicas incompatíveis com o sistema capitalista de livre empresa, livre comércio e investimento. Por outro lado, Hobsbawm colocou também que, em qualquer avaliação racional, a União Soviética não representava perigo imediato ao mundo fora do alcance das forças do Exército Vermelho, pois saíra da guerra em ruínas e em crise. Contudo, por não estar disposta a fazer concessões aos Estados Unidos, engajou-se na política de confrontação dos dois lados que sustentou a Guerra Fria: os Estados Unidos preocupavam-se com o perigo de uma suposta supremacia soviética, enquanto a União Soviética preocupava-se com a hegemonia norte-americana de fato existente e exercida em todas as partes, exceto nas áreas ocupadas pelo Exército Vermelho.

Ao longo da história dos Estados Unidos, a observação das ações tomadas pelo país permite reconhecer a manutenção e a preservação de um conjunto de concepções nascidas e desenvolvidas desde a República, em 1776. Tais concepções, durante os anos, foram incorporadas, ganharam novos nomes, foram perseguidas de formas diferentes, ou seja, adaptaram-se ao contexto e acompanharam o desenvolvimento da nação. Apesar das transformações dos cenários interno e mundial, portanto,

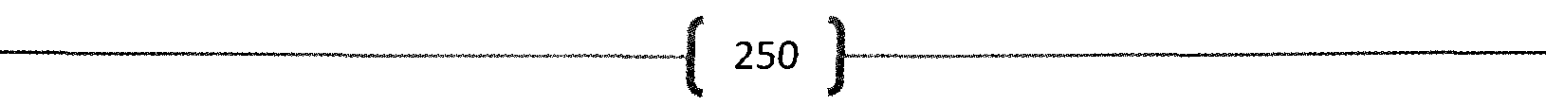


determinadas características morais mantiveram-se como princípios fundamentais para a definição do interesse nacional norte-americano e para a formulação de suas políticas, revelando-se permanentes e recorrentes na construção dos Estados Unidos como nação e civilização. (PECEQUILO, 2005)

No final da década de 1980, Jean-Pierre Fichou escreveu a obra "A civilização Americana" 4 com o intuito de analisar as teorias explicativas dos Estados Unidos através do resgate de seus componentes essenciais e da compreensão de seu caráter cultural. Segundo Fichou, as teorias explicativas são tentativas de explicação da civilização americana, que bastam-se a si mesmas e constituem a base da cultura nacional norte-americana. Em sua obra, Fichou analisa e expõe diversos aspectos culturais da sociedade americana e demonstra como esses constituem "um todo bastante homogêneo no tempo, apesar das variações setoriais ou locais, apesar das modas e das crises" (FICHOU, 1990: 7). Os aspectos culturais da sociedade americana analisados por Fichou explicam muitos dos princípios morais exaltados pelos cidadãos e políticos norte-americanos e

\footnotetext{
4 Jean-Pierre Fichou nasceu em 1935. Foi professor visitante do Kalamazoo College em Michigan, nos Estados Unidos. Além de Professor-assistente e Mestre de Conferências na Universidade de Caen, foi também diretor do Laboratório de Línguas e do centro de Formação Permanente em Línguas de Caen, na França. A obra original, em francês, da editora PUF, intitula-se " $\mathrm{La}$ civilizasation américaine" e foi publicada em 1987.
} 
expressam não apenas a forma de ver a si mesmo e de agir dentro de seu território, como a forma de ver o outro e de agir ante as ações do outro.

De Roosevelt, em 1945, a Bush, em 1989, todos os presidentes da Guerra Fria mencionaram em seus discursos inaugurais a defesa e a manutenção dos princípios morais dos Estados Unidos. Apesar de cada discurso ter sido produzido em circunstâncias diferentes, os elementos se repetem constantemente. Em um período de mudanças e de defesa da transição de uma política tradicionalmente isolacionista para uma nova política de posicionamento como potência na construção de uma nova ordem mundial, Roosevelt propõe em 1945:

Nós devemos nos esforçar pela perfeição. Nós não a alcançaremos imediatamente - mas mesmo assim nós devemos nos esforçar. Nós podemos cometer erros mas nunca devem ser erros que resultem da fraqueza de coração ou do abandono de nossos princípios morais. ${ }^{5}$

Por sua vez, já claramente presente o fim da Guerra Fria, com a derrota da União Soviética, Bush disse em 1989: "A América

\footnotetext{
${ }^{5}$ Tradução livre. No original: "We shall strive for perfection. We shall not achieve it immediately - but we still shall strive. We may make mistakes - but they must never be mistakes which result from faintness of 'heart or abandonment of moral principle". (ROOSEVELT, 1945)
} 
nunca é ela por inteiro se não estiver engajada nos mais altos princípios morais". 6

Não é possível compreender Roosevelt e Bush de forma igual sem correr riscos de anacronismo. Entretanto, é possível observar que ambos se encontram em posição semelhante, pois viviam períodos de incertezas, em que a posição dos Estados Unidos no sistema mundial ainda estava obscurecida pela necessidade de agir e pela dúvida de como agir. Cientes do desafio presente, os presidentes assumiram seu papel de líderes e, através do discurso político, procuraram dirigir a nação utilizando-se do argumento da existência de princípios fundamentais a serem seguidos.

Acerca do discurso político, Antoine Prost (1996: 312) coloca que "as maneiras de falar não são inocentes; para além de sua aparente neutralidade, revelam estruturas mentais, maneiras de perceber e de organizar a realidade denominando-a". Assim, os discursos de posse dos presidentes dos Estados Unidos durante o período da Guerra Fria demonstram sobre quais princípios morais o país sustentou-se nesse período. Esse é o papel do governante, do seu discurso, conforme Prost, pois o falante (no caso aqui explorado, os presidentes) apodera-se do papel que lhe convém e atribui aos seus interlocutores (os cidadãos norte-americanos), os papéis que

${ }^{6}$ Tradução livre. No original: "America is never wholly herself unless she is engaged in high moral principles". (BUSH, 1989) 
escolheu para eles. Tradicionalmente, os americanos para aceitarem uma guerra precisam de pretextos sólidos e durante toda a sua história utilizaram-se sempre de uma justificativa grandiosa para suas ações, tornando-as nobres. Assim, os papéis escolhidos pelos presidentes em seus discursos de posse precisam ser compatíveis com aqueles que a sociedade norte-americana atribui a si própria e com os quais identifica-se para conquistar o apoio necessário à manutenção da disputa constante contra a União Soviética.

O discurso de posse do presidente dos Estados Unidos ocorre no dia 20 de janeiro a cada troca de mandato, data de início de mandato do novo presidente. Oficialmente, a única tradição obrigatória é o juramento, entretanto ao longo dos anos, transformouse em um evento de um dia inteiro com direito a paradas, visitas a diversos locais e bailes por todo o país em comemoração a instauração do novo presidente, do exercício da democracia e do que faz dos cidadãos norte-americanos uma nação. Dentre os aspectos da civilização americana apresentados por Fichou (1990), alguns aparecem de forma mais intensa no conjunto dos doze discursos de posse de oito presidentes do período da Guerra Fria ${ }^{7}$ : a democracia, a

7 São nove os presidentes da Guerra Fria, entretanto, Gerald Ford assumiu o mandato após a renúncia de Nixon e, por isso, não foi inaugurado, assim como Truman realizou seu discurso apenas em 1949 e Johnson em 1965 apesar de terem assumido em 1945 e 1963 após a morte de Roosevelt e Kennedy, respectivamente. São aqui considerados, portanto, os seguintes presidentes e as datas de suas 
abundância, o dinamismo, o individualismo, o capitalismo e o expansionismo. Os aspectos culturais da sociedade norte-americana defendidos como princípios morais não são isolados, seus conceitos e interpretações se misturam, se autojustificam e se confundem conforme a situação nas quais são utilizados.

Nascida com a República, a democracia institucionalizou o ideal de liberdade norte-americano ao garantir a existência de um governo caracterizado pelo desejo único da maioria, sensível ao dinamismo, à força do trabalho, ao ardor e à opulência de uma sociedade abundante e igualitária em seu compartilhamento (FICHOU: 20). Iniciado seu desenvolvimento em 1776, a democracia foi contextualizada em 1835 por Alexis de Tocqueville em sua obra "Da democracia na América". Enviado aos Estados Unidos pelo governo francês em 1831 para estudar o sistema prisional americano, Tocqueville relatou não só acerca das prisões, mas sobre todos os aspectos da sociedade dos Estados Unidos, incluindo a sua economia e, sobretudo, seu sistema político, inédito no mundo na época da viagem. Sua obra sobre a democracia tornouse um clássico ao descrevê-la e mostrar como a sociedade norte-

inaugurações: Franklin D. Roosevelt (1945), Harry S. Truman (1949), Dwight D. Eisenhower (1953 e 1957), John F. Kennedy (1961), Lyndon B. Johnson (1965), Richard M. Nixon (1969 e 1973), Jimmy Carter (1977), Ronald Reagan (1981 e 1985) e George Bush (1989). 
americana fez com que ela funcionasse. Segundo Tocqueville, o princípio mais marcante da democracia era o da soberania do povo.

É pelo dogma da soberania do povo que se deve começar a falar das leis políticas dos Estados Unidos. $\mathrm{Na}$ América, o princípio da soberania popular jamais está oculto ou estéril, como em outras nações; ele é reconhecido nos costumes e proclamado nas leis; estende-se com toda liberdade, e alcança sem obstáculos as suas últimas consequências. (TOCQUEVILLE: 09)

Nos discursos presidenciais da Guerra Fria, essa soberania do povo foi exaltada e solicitada em consoante harmonia com os princípios do voluntarismo e do dinamismo. Em 1949, já solidificada a rivalidade entre Estados Unidos e União Soviética, Harry Truman definiu os aspectos da democracia americana em oposição ao comunismo, demonstrando também a construção da versão norteamericana das características comunistas. Nas palavras de Truman (1949):

O comunismo é baseado na crença de que o homem é tão fraco e inadequado que ele é incapaz de governar a si mesmo, e por isso precisa do governo de mestres fortes.

A democracia é baseada na conviç̧ão de que o homem tem capacidade moral e intelectual, assim como o direito inalienável de governar a si mesmo com razão e justiça. 
Cadernos de Clio, Curitiba, n. ${ }^{\circ}$ 2, 2011

$\mathrm{O}$ comunismo submete o indivíduo à prisão sem justa causa, à punição sem julgamento e ao trabalho forçado para o Estado. Ele decreta o tipo de informação que se deve ter, que arte se deve produzir, quais líderes devem ser seguidos, e quais idéias devem ser pensadas.

A democracia sustenta que o governo é estabelecido para o benefício do indivíduo e está encarregado da responsabilidade de proteger os direitos do mesmo e sua liberdade no exercício de suas habilidades.

O comunismo sustenta que erros sociais podem ser corrigidos pela violência.

A democracia comprovou que a justiça social pode ser realizada através de mudanças pacíficas.

O comunismo prega que o mundo é dividido em classes opostas a ponto de a guerra ser inevitável.

A democracia prega que nações livres podem resolver suas diferenças de forma justa e manter a paz. ${ }^{8}$

\footnotetext{
${ }^{8}$ Tradução livre. No original: "Communism is based on the belief that man is so weak and inadequate that he is unable to govern himself, and therefore requires the rule of strong masters. Democracy is based on the conviction that man has the moral and intellectual capacity, as well as the inalienable right, to govern himself with reason and justice. Communism subjects the individual to arrest without lawful cause, punishment without trial, and forced labor as the chattel of the state. It decrees what information he shall receive, what art he shall produce, what leaders he shall follow, and what thoughts he shall think. Democracy maintains that government is established for the benefit of the individual, and is charged with the responsibility of protecting the rights of the individual and his freedom in the exercise of those abilities of his. Communism maintains that social wrongs can be corrected only by violence. Democracy has proved that social justice can be achieved through peaceful change. Communism holds that the world is so widely divided into opposing classes that war is inevitable. Democracy holds that free
} 
Para Pecequilo (2005), ao basear-se na incompatibilidade entre os dois regimes e na necessidade de preservação da integridade da sociedade americana, Truman conseguiu levar o país efetivamente a uma nova forma de engajamento no sistema mundial, levando-o a envolver-se na construção e na administração da nova ordem. É importante lembrar que em março de 1947 Truman fez outro discurso de defesa da democracia, que lançou as bases para sua doutrina, de defesa dos elos mais "fracos" da democracia sob o perigo comunista. A ênfase não era no capitalismo explicitamente e, sim, em regimes democráticos e na liberdade. Assim, percebe-se que, desde o primeiro discurso em clima de Guerra Fria, a exaltação da democracia justificou e deu legitimidade ao governo americano e ao estilo de vida de sua sociedade. A democracia foi defendida como o regime político mais adequado aos Estados Unidos, pois possibilitou o desenvolvimento do capitalismo e se opôs ao regime político soviético, caracterizado pelos americanos como comunismo ditatorial.

Acompanhando o princípio da democracia, os discursos de posse trazem também o voluntarismo como parte da soberania do povo. O povo elege seu governo, mas a vontade de agir não é

nations can settle differences justly and maintain a lasting peace". (TRUMAN, 1949) 
limitada a ele e é desse voluntarismo, dessa vontade de agir sobre o mundo, os outros e sobre si mesmo que a soberania do povo é legitimada. A famosa frase do discurso de Kennedy em 1961, "Não pergunte o que a América fará para você - mas o que juntos podemos fazer pela liberdade do homem" 9 , celebra esse voluntarismo. Da mesma forma, Carter, em 1977, lembrou a importância do voluntarismo popular para transformar em prática as propostas de um novo governo: "Essa cerimônia inaugural marca um novo começo, uma nova dedicação dentro de nosso governo e um novo espírito entre nós. Um presidente pode sentir e proclamar esse novo espírito, mas apenas um povo pode fornecê-lo" ${ }^{10}$. A aceitação do voluntarismo pela sociedade norte-americana em 1961 e em 1977 foi completamente diferente: Kennedy teve o apoio da população na sua intensificação da corrida armamentista, enquanto Carter não convenceu ao defender uma política menos agressiva ao comunismo. Tal diferença pode ser identificada como conseqüência da intensa presença da tensão bélica no cotidiano dos norte-americanos.

\footnotetext{
9 Tradução livre. No original: "My fellow citizens of the world: ask not what America will do for you, but what together we can do for the freedom of man". (KENNEDY, 1961)

10 Tradução livre. No original: "This inauguration ceremony marks a new beginning, a new dedication within our Government, and a new spirit among us all. A President may sense and proclaim that new spirit, but only a people can provide it". (CARTER, 1977)
} 
O povo, portanto, é ativo, sustentado pelo seu dinamismo. De acordo com Fichou, a sociedade americana não suporta a inércia e é essa aversão à inércia que mantém o povo americano sempre olhando para o futuro, imaginando-o e planejando como agir para que ele seja diferente do passado. Nixon questionou: "Que tipo de nação nós seremos, em que tipo de mundo nós viveremos? Se nós moldarmos o futuro na imagem de nossas esperanças, é nosso poder determinar pelas nossas ações e escolhas" "11. O dinamismo une-se ao voluntarismo para criar uma imagem encantada e otimista do futuro. Segundo Fichou (1990: 44), e como demonstram as palavras de Nixon expressas acima, "o amanhã será melhor se soubermos aproveitar nossas oportunidades". E essas oportunidades são constantes em um país abundante em recursos e riquezas como os Estados Unidos.

A civilização americana, portanto, é dinâmica e otimista porque é abundante. A abundância americana gera sempre novas conquistas e oportunidades iguais para todos, sustentando junto com a democracia o ideal de igualdade e liberdade: aqueles que melhor souberem servir-se da abundância e da liberdade servir-se-ão primeiro. A liberdade, portanto, é protegida pela abundância, pois lhe

\footnotetext{
${ }^{11}$ Tradução livre. No original: "What kind of a nation we will be, what kind of a world we will live in, whether we shape the future in the image of our hopes, is ours to determine by our actions and our choices". (NIXON, 1969)
} 
Cadernos de Clio, Curitiba, n. ${ }^{\circ} 2,2011$

oferece formas diversas de escolhas e alternativas as quais o cidadão americano é livre para tomar suas decisões.

Além disso, a abundância para os Estados Unidos, como coloca Fichou, não se limita à quantidade de recursos naturalmente disponíveis, mas está também presente na valorização dessas riquezas através do desenvolvimento da indústria, do comércio, da publicidade e do consumo - está presente no sistema econômico dinâmico e capitalista, cujo fím é o aumento da riqueza material dos homens e da nação, garantindo sua crescente abundância e mantendo o ciclo sempre ativo. Como afirmou Eisenhower em 1957:

\begin{abstract}
Nós vivemos em uma terra de abundância, mas essa terra nunca esteve tão em perigo como hoje está. Em nossa nação, trabalho e riqueza abundam. Nossa população cresce. O comércio enche os nossos rios e ferrovias, nossos céus, portos e estradas. Nosso solo é fértil, nossa agricultura, produtiva. $O$ ar soa a música de nossa indústria - tocando os moinhos e fornos, os dínamos, as represas e as linhas de montagem - o refrão da América generosa. ${ }^{12}$
\end{abstract}

\footnotetext{
${ }^{12}$ Tradução livre. No original: "We live in a land of plenty, but rarely has this earth known such peril as today. In our nation work and wealth abound. Our population grows. Commerce crowds our rivers and rails, our skies, harbors and highways. Our soil is fertile, our agriculture productive. The air rings with the song of our industry--rolling mills and blast furnaces, dynamos, dams and assembly lines--the chorus of America the bountiful". (EISENHOWER, 1957)
} 
Questionar a produtividade, portanto, seria ir contra as noções fundamentais da civilização e questionar o próprio sistema, o que o enfraqueceria ante o inimigo comunista. Para Fichou (1990: 94), o capitalismo "baseia-se num certo número de ideias de partida que se harmonizam perfeitamente com a mentalidade americana de sempre". Baseado no dinamismo e na abundância do consumo, da produção e da livre empresa, o sistema capitalista sustenta a democracia e garante a liberdade e a igualdade do indivíduo.

A dinâmica da indústria e o desenvolvimento norteamericano, segundo Fichou, foram essenciais para levar os Estados Unidos a conscientizarem-se de que precisavam ampliar seu território e povoá-lo para desenvolver seu mercado, pois a natureza do capitalismo exigia a produção contínua. O princípio do expansionismo coloca-se, assim, como essencial ao desenvolvimento do capitalismo e ao crescimento da influência americana no sistema internacional. Em seu primeiro discurso de posse, anterior ao acima mencionado, Eisenhower disse:

Nós sabemos que estamos conectados a todos os povos livres não apenas na teoria mas devido às necessidades básicas. Nenhum povo livre pode se ater a qualquer privilégio ou desfrutar de segurança econômica em solidão. Apesar de toda nossa abundância material, até nós precisamos de mercados no mundo para o excesso de nossas fazendas e fábricas. Igualmente, nós precisamos para essas mesmas fazendas e fábricas 
Cadernos de Clio, Curitiba, n. ${ }^{\circ}$ 2, 2011

materiais e produtos vitais de terras distantes. Essa regra básica da interdependência, tão manifesta no comércio da paz, aplica-se mil vezes mais intensamente em tempos de guerra. (EISENHOWER, $1953)^{13}$

O capitalismo é para os Estados Unidos durante a Guerra Fria a melhor forma de garantir sua superioridade em relação à União Soviética, pois a constante preparação de materiais bélicos intensifica as relações comerciais e aumenta a demanda pelos produtos oferecidos pela abundante indústria norte-americana. Devido a esse aspecto econômico, o expansionismo norte-americano pode ser entendido como uma nova forma de imperialismo. Nova porque, como lembra Fichou, os Estados Unidos não são uma potência imperial no sentido literal do termo por não possuírem colônias com as quais exerçam o tipo de relação dos impérios tradicionais. Entretanto, os Estados Unidos exercem uma influência considerável sobre várias nações, o que constitui o caráter neo-imperialista de seu expansionismo. Segundo Fichou (1990: 141), "em vez de enviar as carroças, eles enviam os vendedores. Eles não colocam governadores

${ }^{13}$ Tradução livre. No original: "We know, beyond this, that we are linked to all free peoples not merely by a noble idea but by a simple need. No free people can for long cling to any privilege or enjoy any safety in economic solitude. For all our own material might, even we need markets in the world for the surpluses of our farms and our factories. Equally, we need for these same farms and factories vital materials and products of distant lands. This basic law of interdependence, so manifest in the commerce of peace, applies with thousand-fold intensity in the event of war. " (EISENHOWER, 1953) 
à frente das nações estrangeiras, mas controlam, frequentemente de modo oculto, as economias e, portanto, as culturas". Tal tipo de ação imperialista, entretanto, não é menos perigosa que a clássica, pois as transformações culturais causam abismos entre gerações ao modificar seus modos de vida e as transformações técnicas alteram a forma de pensar e as heranças transmitidas.

O expansionismo norte-americano nesse período não se restringia, portanto, aos aspectos econômicos, visto que a expansão econômica levava consigo a introdução de novas definições culturais e a tentativa de implantar na cultura dos outros países os princípios norte-americanos. Para Fichou, os Estados Unidos, ao esquecerem-se da diferença cultural existente em cada região, visavam a modelar o outro à sua imagem, sem perceber que tal objetivo nem sempre seria possível ou bem recebido. O principal aspecto dessa expansão cultural era o estabelecimento de uma democracia com os mesmos aspectos da americana e o peso dos princípios que a defesa desse regime político levava consigo. Os Estados Unidos eram o exemplo a ser seguido e seguir esse exemplo era imitá-lo, ou seja, copiar o estilo de vida americano transformando as culturas internas de cada região, americanizando-as. Carter, em 1977, disse: "Nossa nação só pode ser forte no exterior se for forte dentro de casa. E nós sabemos que o melhor caminho para aumentar a liberdade em outras terras é 
demonstrando aqui que nosso sistema democrático é merecedor de emulação."14 Apesar desse discurso enfatizar a defesa de uma política mais voltada para as questões internas, exemplifica claramente o ideal norte-americano de servir como exemplo para os outros e um exemplo a ser seguido e imitado. O discurso de Carter demonstra que mesmo em tempos de novas propostas políticas, o ideal e a visão do papel dos Estados Unidos para além de suas fronteiras não deixam de ser o mesmo.

Em sua base o expansionismo é justificado e explicado, segundo Fichou, através do messianismo presente nos princípios americanos desde o surgimento do Destino Manifesto, expresso por John O'Sullivan em 1845: "a revolução mundial que inventará uma nova sociedade nascerá nos Estados Unidos, pela vontade de Deus, que facilmente encontra-se ao lado dos americanos" (FICHOU: 110). Para Pecequilo, o Destino Manifesto racionalizava a expansão pela ideia de dever que os norte-americanos tinham de espalhar e afirmar seu espírito e visão. Assim, os Estados Unidos se entendem como o povo escolhido e esclarecido por Deus que teria não só o direito, mas o dever de expandir seus valores e ideais. Durante o mesmo período de incertezas em que Roosevelt mencionou a manutenção dos

${ }^{14}$ Tradução livre. No original: "Our Nation can be strong abroad only if it is strong at home. And we know that the best way to enhance freedom in other lands is to demonstrate here that our democratic system is worthy of emulation." (CARTER, 1977) 
princípios morais da civilização americana, o presidente lembrou que, apesar de ainda não se ter definida a forma como os Estados Unidos assumiriam as responsabilidades que estavam por vir, Deus iluminaria o povo americano e estaria ao seu lado.

Deus Todo Poderoso abençoou nossa terra em muitos sentidos. Ele deu ao nosso povo corações e braços fortes com os quais desferir fortes golpes em nome da liberdade e da verdade. Ele deu ao nosso país uma fé que tem se tornado a esperança de todas as pessoas num mundo angustiante.

Então nós pedimos a Ele agora a visão para enxergar nosso caminho claramente e ver o caminho que leva a uma vida melhor para nós mesmos e a nossa querida humanidade - e para realizar o desejo Dele de paz na terra. (ROOSEVELT, 1945) ${ }^{15}$

No discurso de posse do segundo mandato de Ronald Reagan estão presentes todos os traços do expansionismo americano em uma só fala. Em nome da liberdade, Reagan comemora o declínio da União Soviética em oposição à vitória dos Estados Unidos como potência econômica e o aumento das democracias no mundo.

${ }^{15}$ Tradução livre. No original: "The Almighty God has blessed our land in many ways. He has given our people stout hearts and strong arms with which to strike mighty blows for freedom and truth. He has given to our country a faith which has become the hope of all peoples in an anguished world. So we pray to Him now for the vision to see our way clearly to see the way that leads to a better life for ourselves and for all our fellow men-and to the achievement of His will to peace on earth". (ROOSEVELT, 1945) 
Contudo, ao comemorar a liberdade como justificativa do expansionismo americano da Guerra Fria, oculta fatos relevantes do período, como o antigo apoio às ditaduras militares na América Latina em nome do anticomunismo e a crescente importância de outras nações capitalistas no cenário econômico mundial. Tais fatos, porém, comprovam o lado incoerente do expansionismo norteamericano e não devem ser mencionados de tal forma, muito menos numa cerimônia comemorativa onde se defendem os princípios norte-americanos.

Nós buscamos por paz e segurança, animados pelas mudanças ao nosso redor. Desde a virada do século, o número de democracias no mundo quadruplicou. A liberdade humana está em marcha, principalmente no nosso próprio hemisfério. Liberdade é uma das aspirações do espírito humano mais profundas e nobres. Pessoas, ao redor do mundo, desejam o direito da autodeterminação, aqueles direitos inalienáveis que tornam o homem digno e o permitem progredir.

A América deve continuar a ser uma leal amiga da liberdade, porque a liberdade é a melhor aliada e é a única esperança do mundo de derrotar a pobreza e preservar a paz. Todo golpe que nós desferirmos contra a pobreza será um golpe contra seus aliados obscuros de opressão e de guerra. Toda vitória da liberdade humana será uma vitória da paz mundial.

Assim, nós seguimos sendo hoje, uma nação poderosa em sua jovialidade e de fortes objetivos. Com nossas alianças fortalecidas, com nossa economia liderando o mundo à uma nova era de expansão econômica, nós 
Cadernos de Clio, Curitiba, n. ${ }^{\circ} 2,2011$

vemos um futuro rico em possibilidades. E tudo isso porque nós trabalhamos e agimos juntos, não como membros de partidos políticos mas como Americanos.

Meus amigos, nós vivemos num mundo iluminado. Muita coisa está mudando e irá mudar, mas muito permanece e transcende o tempo. (REAGAN, 1985) ${ }^{16}$

O discurso de Reagan não só resume o expansionismo da Guerra Fria como utiliza todos os princípios morais aqui trabalhados para justificá-lo e exaltá-lo. O aumento do número de democracias demonstraria a influência dos Estados Unidos e a expansão de seus ideais. A expansão da economia capitalista demonstraria que o fim da Guerra Fria se aproximava com os Estados Unidos saindo vitoriosos. Essa vitória sempre pareceu certa, mas só seria possível se

${ }^{16}$ Tradução livre. No original: "We strive for peace and security, heartened by the changes all around us. Since the turn of the century, the number of democracies in the world has grown fourfold. Human freedom is on the march, and nowhere more so than in our own hemisphere. Freedom is one of the deepest and noblest aspirations of the human spirit. People, worldwide, hunger for the right of selfdetermination, for those inalienable rights that make for human dignity and progress. America must remain freedom's staunchest friend, for freedom is our best ally and it is the world's only hope to conquer poverty and preserve peace. Every blow we inflict against poverty will be a blow against its dark allies of oppression and war. Every victory for human freedom will be a victory for world peace. So, we go forward today, a nation still mighty in its youth and powerful in its purpose. With our alliances strengthened, with our economy leading the world to a new age of economic expansion, we look to a future rich in possibilities. And all of this is because we worked and acted together, not as members of political parties but as Americans. My friends, we live in a world that's lit by lightning. So much is changing and will change, but so much endures and transcends time". (REAGAN, 1985) 
o povo americano mantivesse viva a consciência de sua capacidade material, pois sua nação sempre foi abundante, e de sua capacidade social, pois o povo permaneceria ativo através de seu dinamismo e voluntarismo.

Analisar os discursos de posse dos presidentes norteamericanos durante o período da Guerra Fria a partir da observação dos aspectos da cultura americana apresentados por Jean-Pierre Fichou nos permite compreender melhor a sociedade norteamericana e como ela se compreende. Apesar dos anos de Guerra Fria não terem sido estáveis, apresentando fases de maior e menor intensidades ou crises, os princípios defendidos pelos presidentes dos Estados Unidos durante o período para justificar a posição da nação ante o mundo e amenizar suas consequências - nem sempre previsíveis - permaneceram semelhantes. Essa análise nos permite, portanto, refletir sobre a construção identitária dos Estados Unidos e sobre suas escolhas, procurando compreender que suas ações são reflexos não só de suas necessidades, mas de demandas de valores que constituem a identidade nacional. 


\section{REFERÊNCIAS BIBLIOGRÁFICAS \\ Obras consultadas}

ABBOTT, Philip. Cold War. In: __ Political thought in America: conversation and debates. Itasca, Illinois: F. E. Peacock Publishers Inc, 1991.

FICHOU, Jean-Pierre. A civilização Americana. Tradução de Maria Carolina F. de Castilho Pires. Campinas: Papirus, 1990.

HOBSBAWM, Eric. Era dos extremos. O breve século XX. 19141991. São Paulo: Companhia das Letras, 1995.

KARNAL, Leandro; PURDY, Sean; FERNANDES, Luiz Estevam; MORAIS, Marcus Vinícius de. História dos Estados Unidos. Das origens ao século XXI. 2 ed. São Paulo: Contexto, 2008.

PECEQUILO, Cristina Soreanu. A política externa dos Estados Unidos. Continuidade ou mudança? 2 ed. Porto Alegre: Editora da UFRGS, 2005.

PROST, Antoine. As palavras. In: Por uma história politica. Rio de Janeiro: Editora UFRJ, Fundação Getúlio Vargas, 1996.

TOCQUEVILlE, Alexis. Democracia na América. Fragmentos. Clube do livro liberal. Disponível em: $<$ http:// www.libertarianismo .com/ livros/ AT-Democracianaamerica.pdf $>$ Acesso em: $12 \mathrm{dez}$ 2009. 
VIZENTINI, Paulo Fagundes. Da Guerra Fria à crise. Relações internacionais do século 20. 4 ed. Porto Alegre: Editora da UFRGS, 2006.

\section{Fontes}

BUSH, George. Inaugural Address. January 20, 1989. Disponível em: $\quad<$ http://www.presidency.ucsb.edu/ws/index.php?pid=16610> Acesso em: 26 nov 2009.

CARTER, Jimmy. Inaugural Address. January 20, 1977. Disponível em: $\quad<$ http://www.presidency.ucsb.edu/ws/index.php?pid=6575> Acesso em: 26 nov 2009.

EISENHOWER, Dwight D. First Inaugural Address. January 20, 1953. Disponível em: <http:// www.presidency.ucsb.edu/ ws/index.php?pid=9600> Acesso em: 26 nov 2009.

. Second Inaugural Address. January 20, 1957. Disponível em: $<$ http:// www.presidency.ucsb.edu/ ws/index.php? pid=10856> Acesso em: 26 nov 2009.

JOHNSON, Lyndon B. Inaugural Address. January 20, 1965. Disponível em: <http:// www.presidency.ucsb.edu/ ws/index.php? pid=26985> Acesso em: 26 nov 2009. 
KENNEDY, John F. Inaugural Address. January 20, 1961. Disponível em: <http:// www.presidency.ucsb.edu/ ws/index.php? pid=8032> Acesso em: 26 nov 2009.

NIXON, Richard. First Inaugural Address. January 20, 1969. Disponível em: <http:// www.presidency.ucsb.edu/ ws/index.php? pid=1941> Acesso em: 26 nov 2009.

. Second Inaugural Address. January 20, 1973. Disponível em: $<$ http:// www.presidency.ucsb.edu/ ws/index.php? pid=4141> Acesso em: 26 nov 2009.

REAGAN, Ronald. First Inaugural Address. January 20, 1981. Disponível em: <http:// www.presidency.ucsb.edu/ ws/index.php? pid=43130> Acesso em: 26 nov 2009.

. Second Inaugural Address. January 20, 1985. Disponível em: $<\mathrm{http}: / / \quad$ www.presidency.ucsb.edu/ ws/index.php? pid=38688> Acesso em: 26 nov 2009.

ROOSEVELT, Franklin D. Fourth Inaugural Address. January 20, 1945. Disponível em: <http:// www.presidency.ucsb.edu/ ws/ index.php?pid=16607> Acesso em: 26 nov 2009.

TRUMAN, Harry. Inaugural Address. January 20, 1949. Disponível em: <http:// www.presidency.ucsb.edu/ ws/index.php? pid=13282> Acesso em: 26 nov 2009. 